ACCEPTED MANUSCRIPT

\title{
Application of a dielectric barrier discharge plasma for heating plastic materials
}

To cite this article before publication: Daniele Borin et al 2019 Plasma Res. Express in press https://doi.org/10.1088/2516-1067/ab1038

\section{Manuscript version: Accepted Manuscript}

Accepted Manuscript is "the version of the article accepted for publication including all changes made as a result of the peer review process, and which may also include the addition to the article by IOP Publishing of a header, an article ID, a cover sheet and/or an 'Accepted

Manuscript' watermark, but excluding any other editing, typesetting or other changes made by IOP Publishing and/or its licensors"

This Accepted Manuscript is @ 2019 IOP Publishing Ltd.

During the embargo period (the 12 month period from the publication of the Version of Record of this article), the Accepted Manuscript is fully protected by copyright and cannot be reused or reposted elsewhere.

As the Version of Record of this article is going to be / has been published on a subscription basis, this Accepted Manuscript is available for reuse under a CC BY-NC-ND 3.0 licence after the 12 month embargo period.

After the embargo period, everyone is permitted to use copy and redistribute this article for non-commercial purposes only, provided that they adhere to all the terms of the licence https://creativecommons.org/licences/by-nc-nd/3.0

Although reasonable endeavours have been taken to obtain all necessary permissions from third parties to include their copyrighted content within this article, their full citation and copyright line may not be present in this Accepted Manuscript version. Before using any content from this article, please refer to the Version of Record on IOPscience once published for full citation and copyright details, as permissions will likely be required. All third party content is fully copyright protected, unless specifically stated otherwise in the figure caption in the Version of Record.

View the article online for updates and enhancements. 


\title{
Application of a dielectric barrier discharge plasma for heating plastic materials
}

\author{
Daniele Borin $^{1}$, Orfeo Sbaizero ${ }^{1}$, Nicola Scuor ${ }^{1}$ \\ ${ }^{1}$ Dept. of Engineering and Architecture, University of Trieste \\ Via A. Valerio 10, 34127 Trieste, ITALY
}

\begin{abstract}
Dielectric barrier discharge (DBD) plasma is usually referred in literature as a form of cold plasma. Many applications of DBD plasma rely on this characteristic, which allow to treat also sensitive materials, including biological tissues, to exploit a range of differenteffects. Atmospheric pressure plasma treatment is regularly used on polymers to enhance surface properties such as wettability and adhesion. However, in the present work, we show that DBD plasma can also be used as an alternative for heating polymeric based materials, as an initial step for further industrial processing such as thermo-forming. In particular, the efficiency of the heating process has been measured, and a novel heating mechanism has been proposed based on the experimental results.
\end{abstract}

Keywords: Dielectric barrier discharge, DBD, polymers, heating, forming 


\section{INTRODUCTION}

Dielectric-barrier discharge (DBD) plasma is created by an electrical discharge between two electrodes separated by an insulating dielectric barrier. It was first reported by Ernst Werner von Siemens in 1857 [1]. Plasmas are generated applying high voltages to the electrodes, which are divided by a gap (Figure 1). This gap is usually filled with a mixture of gases, often at values near to the atmospheric pressure. One (or both) of the electrodes is covered with a dielectric layer, which is commonly provided using glass, quartz, ceramic or plastic materials. This layer avoids the formation of thermal arcs when the system is powered, whereas the gaseous dielectric undergoes a disruptive discharge. In the DBD process, the electrodes are connected to a high voltage alternating current (HV AC) source. In order to achieve a stable DBD performance, frequency ranges usually from some tens of $\mathrm{Hz}$ up to the order of several $\mathrm{kHz}$, with amplitudes from 1 to $100 \mathrm{kV}$ [2-3].

DBD consists of a multitude of short current filaments [4]. Due to the brief duration of these micro discharge channels and the dominant low ion mobility, the kinetic energy is mainly conveyed to electrons, which become heated, unlike the other species. This behavior provides a significant electronic excitation of molecules. Therefore, the plasma fosters efficient thermo-chemical reaction processes. The discharge filaments are normally visible to the naked eye as a purple-violet radiation, when the gaseous dielectric is simply air at the normal pressure of 1 bar. Each of them is a channel of conducting plasma, and its terminal part on the side of the dielectric interface represents the area where a surface charge has been accumulated during discharge.

The geometry of a DBD plasma generator can vary widely based on the chosen application, ranging from simple planar devices (Figure 1), to coaxial cylindrical generators, to more complex-shaped devices. In the case of the coaxial configuration, the dielectric is shaped in the same form as common fluorescent tubing. The device is filled at atmospheric pressure with either a rare gas or rare gashalide mix, with the glass walls acting as the dielectric barrier. Due to the atmospheric pressure level, such processes require high energy levels to sustain.

DBD systems are experiencing a wide range of applications, also in industrial processes. Excimer lamps, exploiting the relaxation of excited species in the plasma (typically in the UV and DUV bands), can be used for sterilization and large-scale generation of ozone.

\section{Fig.1 Typical DBD plasma setup}


Optical industry exploits DBD plasma as a pumping system for high-power laser generators based on a gaseous active medium, e.g. in excimer or $\mathrm{CO}_{2}$ lasers. High-efficiency DBD light sources are under study and development, taking advantage of the abandoned technology of plasma display panels (PDP) [5]. DBD plasma systems are also industrially employed for the modification or cleaning of surfaces, e.g. in the field of plastic, glass and semiconductor materials, to improve properties like wettability, adhesion or printability [6]. The gap distance between electrodes varies considerably among these devices, from less than $0.1 \mathrm{~mm}$ in plasma displays, to several millimeters in ozone generators and up to several centimeters in $\mathrm{CO}_{2}$ lasers.

DBD plasma is also capable of decomposing chemical substances, which can be usefully exploited in processes related to the synthesis of chemical compounds or pollution control $[7,8]$. The fluid dynamics interaction between airflows and DBD plasma makes it interesting also in active flow control applications, where the lack of mechanical parts, lightness and high response frequency represent a decisive advantage over mechanical actuators in modern aircrafts technologies [9]. The development of safe and efficient DBD plasma sources led also to the development of biomedical applications of plasmas, defined as "plasma medicine".

Most of the application fields for DBD outlined above take advantage of relatively low temperature of DBD plasma, if compared to thermal plasma. DBD is therefore suitable for treating heat sensitive materials, including live biological tissues. Moreover, it is noticeable the fact that DBD plasma can be generated at atmospheric pressures, using a variety of supporting gases or gas mixtures, including air.

This paper describes the thermal effects of DBD plasma on the dielectric barrier itself. This topic, to the best of our knowledge, gained little attention in the literature. Nevertheless, it will be shown that the heating of the dielectric barrier due to DBD plasma is an interesting effect, particularly when a plastic material that needs to be preheated for further processes provides the dielectric barrier. Such material could be, for example, a plastic film which needs to be thermoformed or vacuum-formed, or a plastic preform which needs to be properly softened to be blown or stretch-blown, as it is typical e.g. in the manufacturing process of plastic bottles and containers.

In industrial processes, the plastic component has to be taken above its glass transition temperature $\left(\mathrm{T}_{\mathrm{g}}\right)$, and therefore in its rubbery state to be easily deformed. This is usually accomplished using radiant sources of heat, based on infrared, relatively low-temperature emitters, or on halogen lamps. Radiant heat transfer has, as a drawback, the irregular temperature distribution below the surface of the heated material. In particular, the temperature gradient will depend (i) on its absorbance coefficient as a function of wavelength, (ii) on its thermal capacity, (iii) conductivity and (iv) diffusivity. The heating model used to assess the temperature gradient involves normally both the Lambert and Beer law for the heat deposition, and the non-stationary Fourier law for the heat flows and temperature profile [10]. Aiming to a better control of the temperature profile, most of the heating 
devices and plants manufacturers provide a convective cooling system, usually a fan, which blows air at room temperature on the surface of the plastic material. The use of such a system, which is extensively used e.g. by the PET bottles manufacturers, tends to strongly reduce the efficiency of the heating systems (down to only 20\%), since it consists in a deliberate energy loss and waste [11-13]. Our research offers an alternative to the radiating heating systems, based on the use of DBD plasma. Its efficiency can be higher than that of radiating systems, while potentially ensuring a better uniformity of the temperature profile. For its peculiar nature, DBD plasma is probably not well suited for heating complex 3D shapes, nevertheless it could be very useful for the processing of simple shapes i.e. films, tubes or hollow cylinders (preforms).

The main contributions of this paper are:

- A description and experimental testing of a novel method for preheating plastic materials for further processing.

- A measure of the energetical efficiency of the aforementioned method.

\section{EXPERIMENTAL SETUP}

\subsection{Heating efficiency of a DBD plasma system}

The aim of these experiments was to measure the heating efficiency of a DBD plasma system in heating a plastic sample confined in the plasma region. The heating efficiency has been assessed measuring the fraction of the total heating energy made available within the plasma, which transforms in sample sensible heat. The remaining fraction of the available energy can be considered as a system loss, which should be minimized if a high heating efficiency must be obtained.

In more detail, an instantaneous power balance for the system composed by plasma power supply and DBD inter-electrodes volume can be described as:

$$
P_{\text {grid }}=P_{\text {gen }}+P_{p}+P_{\text {other }}
$$

Where:

$P_{\text {grid }}$ is the electric power withdrawn from the electric power grid, $P_{g e n}$ is the power dissipated as heat by the DBD power supply, for power conversion, $P_{p}$ is the total power dissipated in the DBD inter-electrodes volume or transferred to the plastic material, and $P_{\text {other }}$ it the power dissipated by cables, and other accessories, used to connect the DBD electrodes to the DBD power supply

$P_{\text {other }}$ can be omitted in the power balance, since it is a small term with respect to the other terms which are present in eq. 1 , so that it can be reasonably neglected. In addition, the term $P p$ can be written as:

$P_{p}=P_{s}+P_{d i s s}$ 
Where Ps is the thermal power which heats up the plastica sample, and $P_{\text {diss }}$ is the energy dissipated by plasma (e.g. in form of air heating, electromagnetic radiation, noise, etc.). The relative efficiencies can be defined as:

$\eta_{\text {glob }}=\frac{P_{s}}{P_{\text {grid }}}$
$\eta_{\text {gen }}=\frac{P_{p}}{P_{\text {grid }}}$

$\eta_{D B D}=\frac{P_{S}}{P_{p}}=\frac{P_{S}}{P_{S}+P_{\text {diss }}}$

Which are, respectively, the global efficiency of the system, the efficiency of the electric generator, and the heating efficiency of the plastic material when the considered system is the DBD interelectrodes volume alone.

By combining eq. 2, 3 and 4, the following expression for the global efficiency of the system can be written:

$\eta_{\text {glob }}=\eta_{g e n} \cdot \eta_{D B D}$

We focused our attention on the measurements made to assess the values of $\eta_{D B D}$, since it is known from the literature that the values of $\eta_{G E N}$ can be quite high, thanks to the charcteristics of novel circuit topologies used for DBD power supply (e.g. pulsed DBD), and to the improving characteristics of the semiconductors used as power switches in the practical implementations of said circuits. In practical terms, reasonable values of $\eta_{G E N}$ in the range 0.70.85 can be reasonably met $[18,19,20]$, so that any value of $\eta_{D B D}$ greater of $0.35-0.4$ could be of potential interest for industrial applications.

For these reasons, aiming to focus our attention to the heating process itself, and not to the characteristics of the generator, a simple sinusoidal output DBD power supply has been used in the experiments. Moreoyer, an average heating efficiency has been assessed considering a heating time $t$ with a value specified below, defined as:

eff $=\frac{\int_{0}^{t} P_{S}(t) d t}{\int_{0}^{t} P_{p}(t) d t}=\frac{Q_{S}}{E_{p}}$

where $E_{p}$ as the total energy made available within the plasma in a certain exposure time, and $Q_{s}$ the thermal energy accumulated in the sample during the experiment, and eff is the DBD heating process efficiency under investigation.

In our case, two independent measurements are needed: (i) the instantaneous plasma power that, by time integration, leads to the total available energy, and (ii) the increase in sensible heat of the sample. For the first measurement, a DBD power supply, a profiled-electrodes cell (Figure 2) and the relative measuring setup (Figure 3 ) has been realized. The power supply consists of a low frequency, resonant- 
type, high-voltage power supply, able to operate in the 10 to $40 \mathrm{kHz}$ frequency range. It was designed and built following the plans of the PVM500-400 power supply, published by the Company Information Unlimited (Amherst, NH), The original plans were modified adding the components necessary for the measurement of the electrical characteristics of interest. It should be emphasized that, following the details given in the introduction, this DBD power supply was not chosen to fulfil the needs of maximizing the global efficiency of the proposed heating system, since it is well known, and it has been referenced, that there are devices on the market and under development which are much more performing. We focused our attention on the actual energy transfer from the energy source (the DBD plasma) to heated plastic material, since this is the actual limiting factor e.g in NIR plastic heating, due to the anticipated problems (temperature profile, thermal runaway, etc.). The results which will be given are thus referred only to the core heating mechanism, which depends on the physics law governing heat generation and transfer. Moreover, an accurate measurement of the actual plasma energy has been performed, to make the analysis reasonably independent from the actual technology which can be actually exploited to generate the plasma itself (e.g. resonant generators, pulsed generators. etc.).

The power supply was designed to operate near its series resonant frequency, which is determined by the leakage inductance of the and the equivalent capacitance of the DBD profiled-electrodes cell. Therefore, when the voltage is too low for discharges to happen, the voltage waveform applied to the discharge electrodes is almost purely sinusoidal, while it substantially modifies when DBD plasma ignites.

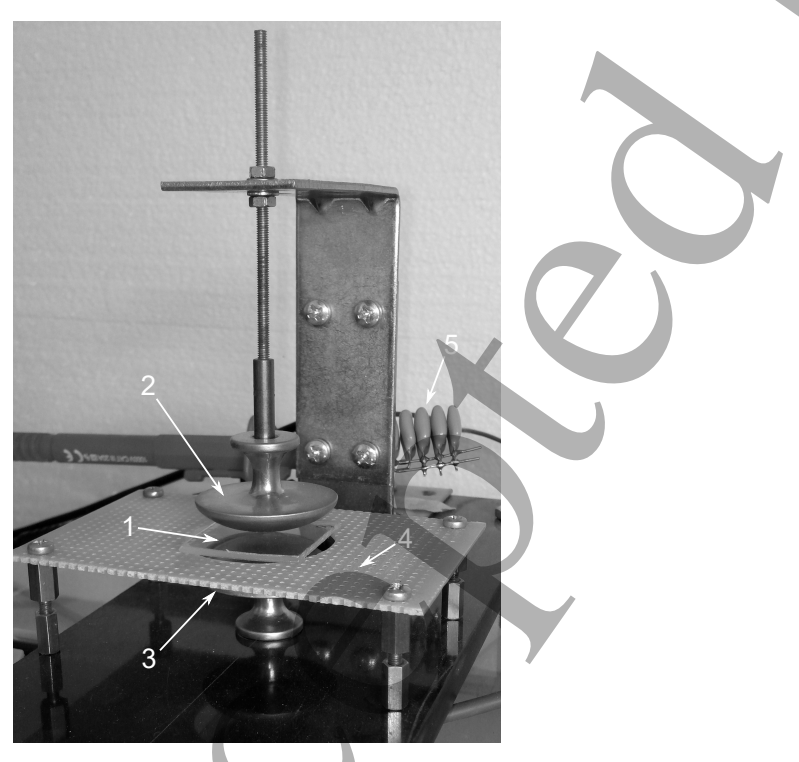

Fig. 2 Plasma application head-1. Sample, 2. Upper electrode, 3. Lower electrode, 4. Sample support, 5. Measuring capacitors

The reactor cell is composed of two electrodes profiled following Ernst theory [14], aiming to maximize electric field uniformity in the interelectrode volume while minimizing the possibility of side discharges. This will create, in the working volume, a reasonably uniform plasma power density, 
essentially a tall cylinder of about $20 \mathrm{~mm}$ diameter. The electrodes were made of nickel coated copper. The dielectric barrier required for DBD operation, which in our case is also the material under investigation, is suspended in the inter-electrode gap through an insulating frame. The thickness of the aforementioned gap can be arranged to be up to $8 \mathrm{~mm}$, allowing also relatively thick plastic sheets to be treated.

Fig. 3 Plasma power measuring setup

The plastic samples are cut from commercial sheets in the form of small squares with an edge dimension of about $30 \mathrm{~mm}$. This allows for proper plasma ignition, without the risk of development of side arcs running around the edge of the sample.

The top electrode is grounded by interposition of a high-quality mica-type measuring capacitor (Fig. 2), whose nominal capacitance $(4.1 \mathrm{nF})$ is much larger than that of the DBD profiled-electrodes cell. The measuring setup for plasma power implements the Lissajous method, as described in $[15,17$, 21]. With reference to Fig. 3, the voltage across the measuring capacitor, which is proportional to the transferred charge [15], is fed to the Digital Storage Oscilloscope (DSO) through a high-bandwidth differential voltage probe (Pico Technology model TA057). This configuration aims to reduce the errors due to the possible voltage drops that could exist along the return path wire. The top electrode is connected to the hot end of the HV power supply and to a voltage divider, which is composed of a $\mathrm{HV}$, non-inductive resistor with a nominal value of $1 \mathrm{G} \Omega$ (model HS76, 3RLab) and the input resistance of the DSO, which has a typical value of $1 \mathrm{M} \Omega$. This produces a voltage dividing ratio of about 1:1000, which is well matched to the input range of the DSO up to the maximum output voltage of the $\mathrm{HV}$ generator $(30 \mathrm{kV})$. In any case, to avoid possible damages to the oscilloscope due e.g. to arcing across the HV resistor, this input was protected with a miniature gas discharge surge protector. Furthermore, the HV readout input was frequency compensated to maximize the setup bandwidth, using a set of fixed capacitors, together with an adjustable compensator.

The setup presented has the advantage of not requiring the use of a high-bandwidth DSO, since the measuring principle is based on integration $[15,16]$. Thus, an inexpensive instrument has been used 
(Rigol DS1054Z), which has been interfaced to a laptop through an USB port. The acquisition software has been written in Labview, and the communication with the DSO has been managed with VISA drivers. The software provides data acquisition and elaboration following the theory described in $[15,16]$, thus providing a real-time plot of the plasma power, and consequently, by time integration, the emitted plasma energy.

The second measurement, i.e the amount of energy transferred from the plasma to the sample as sensible heat, has been fulfilled using a simple calorimeter designed to fit the sample size, thus maximizing the instrument sensitivity, as represented in Fig. 4 It has been manufactured from an extruded polystyrene block, to fit the shape of the samples used, in order to minimize the quantity of water used, thus enhancing the instrument sensitivity. Sample has been suspended inside the calorimeter by means of small plastic pins inserted into the cavity before sealing it, to minimize the contact between sample and cavity walls during the measurements.

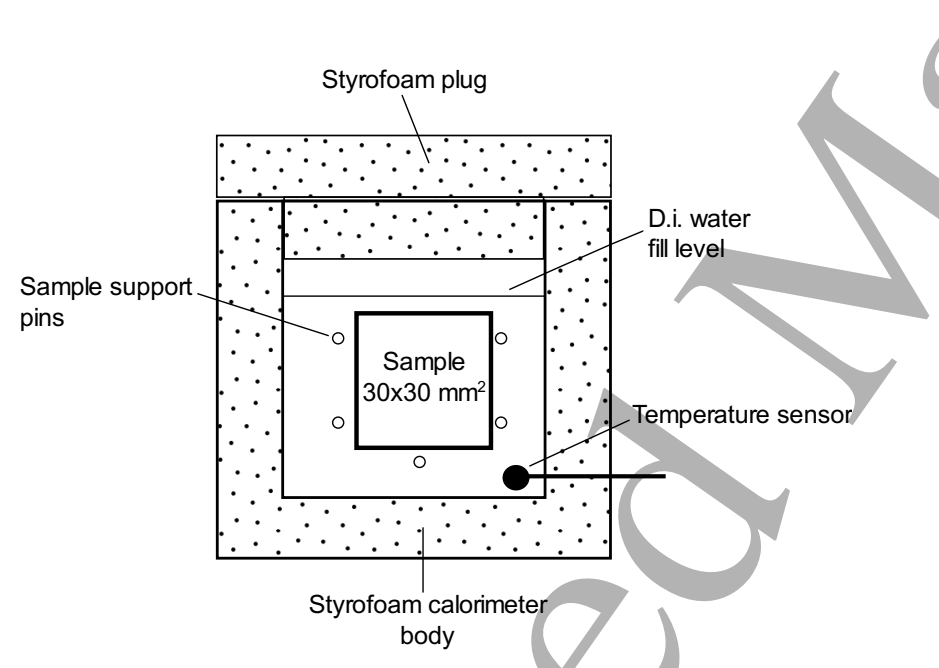

Fig. 4 Calorimeter setup

For the sake of simplicity, deionized water (DI) has been chosen as the working fluid. Temperature measurements has been made by a K-type, kapton insulated thermocouple. National Instruments hardware has been used (NI cRIO 9024 with thermocouple input module NI 9211) as the input device, and the relative software has been written in Labview, allowing for full integration with the data stream coming from the DSO. 
It should be noted that the temperature increase in the sample due to plasma exposition should not be considered uniform within its volume. Nevertheless, if (i) before the beginning of the experiment, the plastic sample temperature is uniform and equal of that of the water inside the calorimeter, and (ii) the same holds for the sample plus water system, a simple relation holds inside the calorimeter after the beginning of the heating phase. In fact, by expressing the following parameters,

$m_{s}$ : mass of the plastic sample $[\mathrm{kg}]$

$m_{\mathrm{W}}:$ mass of the water $[\mathrm{kg}]$

$T_{i}$ : initial, common temperature of sample and water

$T_{f}$ : final, equilibrium temperature of both the sample and water system, inside the calorimeter $c_{p s}, c_{p w}:$ specific heat of, respectively, sample material and water $[\mathrm{J} /(\mathrm{kg} \mathrm{K})]$

and considering an ideal case (no energy losses during sample transfer, and from the calorimeter, uniform final temperature inside the calorimeter, constant $c_{p s}$ ), the following, simple relation holds for $Q$ :

$Q_{s}=\left(m_{w} c_{p w}+m_{s} c_{p s}\right)\left(T_{f}-T_{i}\right)$

During the experiments, $T_{f}$ has been kept well below the glass transition temperature of the plastic material tested, to make sure that $c_{p s}$ varies as little as possible.

As a precaution against equilibrium temperature overestimation, the thermocouple has been placed in a lower corner of the measuring chamber, i.e. the point where a positive effect of stratification is reduced. Moreover, a set of dimples which are present on the inner surface of the calorimeter, guarantees the minimum contact between the sample and the calorimeter walls, to reduce the heat transfer by conduction at a practical minimum. For the same reasons, the wall itself are made with a low-conductivity material, which is expanded polystyrene.

However, it has to be noted that in the real case, some heat losses are still present during the experiments, which decrease the final equilibrium temperature $T_{f}$, thus reducing the value of the estimated efficiency. The reported results therefore reflect a lower bound for the efficiency of the heating mechanism itself.

Accordingly, with the description of the measuring system, the following experimental procedure has been outlined. In a first step, plastic samples of suitable size -e.g. 30 x $30 \mathrm{~mm}$ - were cut from a sheet 
of proper thickness, which can lie from 1 to $2 \mathrm{~mm}$, and carefully weighted. Then, before each experiment, each sample was placed in a beaker, filled with DI water. The samples were allowed to thermally equilibrate with both the measuring fluid, and the temperature of the surrounding environment (which was kept at $20^{\circ} \mathrm{C}$ ). This helps to minimize the errors due to heat losses during sample transfer. To avoid sample water absorption, an insulation barrier was provided using a thin polyethylene (PE) bag, in which samples were placed, and which in turn, was fully submersed in the fluid. Just before the beginning of each experiment, the calorimeter, whose body is supposed to be at the same equilibrium temperature of the samples, was filled with a pre-determined amount of water, which was taken from the same beaker where the samples were stored. Then, the sample was loaded in the DBD profiled-electrodes cell using plastic tweezers, to minimize any heat transfer from the body of the operator to the material under test. Shortly afterwards, the DBD plasma was ignited and let to run for a time defined by trial and error preliminary tests, to account for the aforementioned criterion of keeping $T_{f}$ well below any phase transformation of the material under test (e.g. thermal induced crystallization). Thus, heating times were kept as short as possible, aiming to have a sensible difference between $T_{i}$ and $T_{f}$, while minimizing changes in the specific heats of the materials involved and heat losses. Typical heating time with the power level used during the experiments (5 to $10 \mathrm{~W}$ ) were in the range of 5 to 8 seconds.

At the end of the heating phase, the sample was quickly moved from the reactor to the calorimeter. Then, the temperature was monitored for a couple of minutes, to let the system to equilibrate, while the calorimeter was gently shacked to favor temperature homogenization. The heating due to this mechanical energy input was shown to be negligible with respect to the temperature increase due to the performed experiments. This was done/by preliminary shaking experiments made with the calorimeter filled with water and a plastic sample at uniform, room temperature: no significative temperature increase in the system has been detected under operating conditions similar to that used in the subsequent experiments.

Before the beginning of the experiments, the plasma power measuring system has been checked and calibrated, to account for the uncertainty of the characteristics of the high-voltage component used. As a first step, the value of the measuring capacitor (A) has been assessed using an HP 4192A measuring bridge, yielding a measured value of $4.05 \mathrm{nF}$, which has been used to calibrate the measuring system. The measured reactance of said capacitor has been checked to be mainly capacitive in the frequency range of interest $(20-25 \mathrm{kHz})$, thus confirming the appropriateness of the choice of the capacitor type.

As a second step, the high-voltage measuring network has been calibrated injecting a sinusoidal signal of known amplitude at the HV input by means of a function generator (Krohn Hite 1000), and adding a proper compensation capacitor in parallel with the input impedance, at the DSO input, to get a 
frequency-compensated readout. The resulting scale factor has been used to calibrate the measuring system. The flatness of the frequency response of the system in the aforementioned frequency range of interest has also been checked, and found to be satisfactory.

\section{EXPERIMENTAL PROCEDURE}

Due to its widespread use as a thermoformable packaging material, a commercial, thermoformable PETG (Veralite 200, IBP, Belgium) was chosen as control sample. PETG has the further advantage of being a non-crystallizable PET, thus improving the accuracy of the measurements. Square samples with size 30 by $30 \mathrm{~mm}$ were cut from a $2 \mathrm{~mm}$ thick PETG sheet. Each sample was numbered, and accurately weighted. The thermal proprieties of the materials used were collected from the available technical literature; in particular, for the thermal capacity $\mathrm{C}_{\mathrm{ps}}$ of the PETG, the value of $1.13 \mathrm{~J} / \mathrm{kg} \mathrm{K}$ was chosen, as resulting from the TDS provided by the manufacturer.

All the samples were placed into a PE bag, which has been submersed in deionized water bath, kept at room temperature. During all the aforementioned operations, the data acquisition program was activated. Before the beginning of each plasma heating test, a known volume of water was transferred to the calorimeter, using a micropipette (Pipetman P200, Gilson USA), taking note of the actual room temperature. Thus, the mass of water used in each experiment has been subsequently estimated using the temperature corrected density of the liquid. The calorimeter chamber was kept at the same room temperature of the thermostat before each test, with the cover lid removed, to let it to thermally equilibrate with the surrounding environment. Between two consecutive tests, the system was left to thermally re-equilibrate for at least 4 hours. Every plastic sample was carefully taken from the PE container using plastic-made tweezers, and quickly put in the DBD plasma heating cell. The interelectrode distance was fixed at $6 \mathrm{~mm}$, and the sample was positioned on the middle plane, and supported by the corners with a hollow, insulating frame. Then, the plasma power supply was turned on, while the software was monitoring the plasma power. After plasma shut-off, the sample was quickly removed from the plasma heating cell, and put in the calorimeter, which was sealed, and gently shaken to enhance the thermal exchanges inside the insulated system, to get thermal equilibrium in the shortest possible time.

The collected data were subsequently elaborated using Eq. 1 and 2 to calculate the heating efficiency of the process. As far as the $T_{f}$ is concerned, the value of the equilibrium temperature was chosen without applying any correction related to the calorimeter heat losses. This might probably lead to a slight underestimation of $T_{f}$, which in turns reflects negatively on the value of the estimated efficiency. For the sake of comparison, a sample of Alumina $\left(\mathrm{Al}_{2} \mathrm{O}_{3}\right)$ has also been tested, using the same procedure. 


\section{RESULTS}

The statistical results of the heating tests, based on a set of 5 samples, are reported in Table 1 . Furthermore, Figure 4 show the typical readout of the calorimeter, with some key points highlighted.

\begin{tabular}{|c|c|c|c|c|c|c|c|}
\hline Sample & Mass [g] & $\mathbf{H}_{2} \mathbf{O}$ mass [g] & $\mathbf{T}_{\text {start }}$ & $\mathbf{T}_{\mathbf{e q}}$ & $\mathbf{E}_{\mathbf{p}}[\mathbf{J}]$ & $\mathbf{Q}_{\mathbf{s}}[\mathbf{J}]$ & $\mathbf{E f f}$ \\
\hline 1 & 1.787 & 6.0 & 18.4 & 19.4 & 35.6 & 27.2 & $76.5 \%$ \\
\hline 2 & 1.695 & 6.0 & 18.2 & 19.4 & 40.1 & 31.8 & $79.4 \%$ \\
\hline 3 & 1.695 & 6.0 & 18.4 & 19.3 & 29.1 & 23.0 & $79.3 \%$ \\
\hline 4 & 1.737 & 6.0 & 18.1 & 19.4 & 49.1 & 34.6 & $70.5 \%$ \\
\hline 5 & 1.702 & 6.0 & 18.7 & 19.5 & 34.0 & 23.0 & $67.8 \%$ \\
\hline & & & & & & & \\
\hline & & & & & & Mean & $74.7 \%$ \\
\hline & & & & & & St. dev. & $5.3 \%$ \\
\hline & & & & & & & \\
\hline $\mathrm{Al}_{2} \mathrm{O}_{3}$ & 1.57 & 6 & 19.4 & 21.4 & 260.0 & 52.7 & $20.3 \%$ \\
\hline
\end{tabular}

Table 1. Statistical results of the heating tests

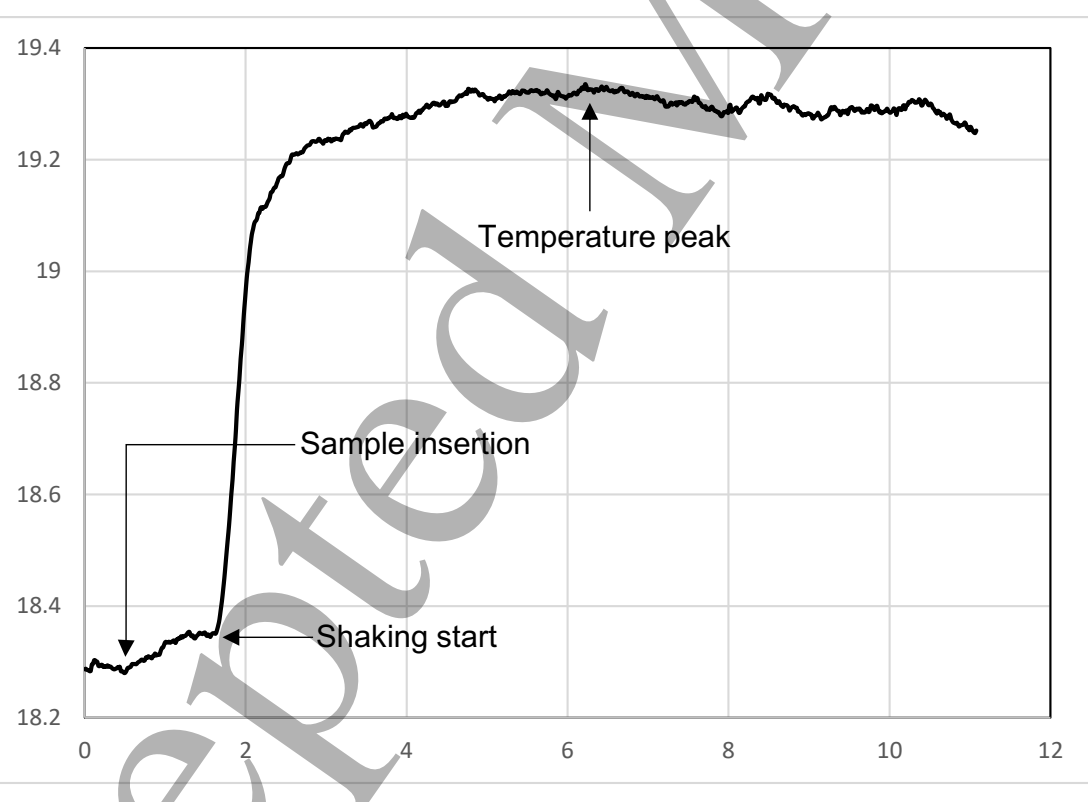

Fig. 4 Data plot from the calorimeter. Horizontal axis: time [min]; vertical axis: temperature $\left[{ }^{\circ} \mathrm{C}\right]$

For completeness of information, the energy absorbed by the DBD power supply from the power grid (in our case, $50 \mathrm{~Hz} \mathrm{AC}$ ) was monitored using a home-built power meter [22], interfaced with the data acquisition system. The measured average efficiency of the generator, calculated as per eq. 2 to 5 , was 0.64 , giving an indicative wall-plug efficiency, in the experimental conditions used, which is 
slightly above $47 \%$, which can be considered remarkably good if compared with the typical wall-plug heating efficiency of the NIR heating system. In evaluating this result, it should be considered that, as previously stated, no significant efforts have been made toward the improvement of the efficiency of the generator.

\section{DISCUSSION}

The results (Table 1) show that the heating efficiency of the system, when applied to PETG,/is remarkably high if compared to that of the conventional heating systems discussed in paragraph 1 . In fact, it shows a lower bound value of about $74 \pm 5 \%$, a value which might be very interesting for most industrial applications. Some facts should be nevertheless considered. First, the heating geometry studied is very simple, consisting in a flat sample and flat electrodes. This limits the potential applicability of the results to a few industrial products, like e.g. those manufactured on a roll-to-roll thermoforming process. However, the beverage industry which currently uses the PETG as a food packaging material requires 3D heating capabilities. Even though there are no theoretical limitations for the outlined process to be adapted in applications where more complex geometries are required, further research is essential to assess the performances and limitations of the system in different situations. Secondly, the reported efficiency refers only to the heating process. In other terms, the efficiency of the plasma power supply, and any other loss which is present in the system was not considered. In a practical implementation of the system, a wall-plug efficiency should be considered, which is beyond the scope of the present research. Nevertheless, it should be noted that the electric efficiency of the modern, solid-state power generators and ancillaries is remarkably high, which suggests that further studies on the system are, worthwhile.

As long as the uniformity of the heating along the samples thickness is concerned, no direct measurements have been made, since the common technique used with conventional heating systems: the "cut and recombined" sample is not appropriate in this case due to arc discharge through the sample thickness. Despite this, some qualitative tests have been made, based on the mechanical thermoforming of the samples just after the heating phase. For this purpose, a dome-shaped punch has been used, with a tip radius of $8 \mathrm{~mm}$. A stretch ratio of 2:1 has been easily obtained, indicating that, despite the short heating times, the sample has been heated enough even in the deepest regions, which is a very promising feature of the proposed technique.

The actual heating mechanism which leads to such high performances will be subject of a future study; nevertheless, the heating performances of the suggested method on the alumina sample can give some insight. In fact, in the case of the ceramic material, the heating efficiency drops to a mere $20 \%$. Based on the currently available data, a viable hypothesis is that the dominant heating mechanism is based on dielectric loss. In fact, the value of this parameter for the two materials measured is quite different 
and this is the reason why alumina is considered a viable substrate for microwave circuits, while PET use in electronics is limited to frequencies below a few hundred $\mathrm{kHz}$ (e.g. as dielectric in capacitors). Moreover, the operating frequency of the DBD power supply is not enough to support a direct observation of the heating, since the power generation by dielectric loss depends on both frequency and the loss tangent of the two materials, which in turns is a function of frequency itself. By a rapid calculation, the dielectric loss power generated in PET at the nominal operating frequency and voltage of our plasma cell is not enough to sensibly heat the material. This has been confirmed operating the plasma cell below the plasma ignition point: no heating of the dielectric barrier can be practically detected under these circumstances. Nevertheless, when DBD plasma streamers forms, the voltage curve shows intense spiking and oscillations, which are present in the inter-electrode gap. This leads to the presence of very high frequency components in the electric field applied to the dielectric material, that can potentially activate the efficient heating mechanisms which have been experimentally proven.

As a further remark, the use of DBD plasma as a heating source could lead, in some industrial sectors, also to some interesting forms of synergy. The same process could become in fact a multi-functional treatment, since heating can be combined with plasma sterilization effects, surface activation, and surface coating.

\section{CONCLUSIONS}

The use of DBD plasma as an efficient heating source for a material of industrial interest has been studied, and the process heating efficiency has been measured for a flat, parallel-electrodes geometry. The results are encouraging, showing a remarkably good heating efficiency of the proposed system. A heating mechanism leading to quite high performances has been proposed. Further extensions of the activity in this field will also include a broader set of materials (e.g. PS, PP, etc.), and different geometries. 


\section{REFERENCES}

\begin{tabular}{|c|c|}
\hline 1 & $\begin{array}{l}\text { Kogelschatz, U., Eliasson, B., Egli, W. } \\
\text { From ozone generators to flat television screens: History and future po- } \\
\text { tential of dielectric-barrier discharges } \\
\text { (1999) Pure and Applied Chemistry, } 71 \text { (10), pp. 1819-1828. Cited } 315 \text { ti- } \\
\text { mes. } \\
\text { DOI: } 10.1351 \text { /pac199971101819 }\end{array}$ \\
\hline 2 & $\begin{array}{l}\text { J. Velikonja, J. A. Robinson, M. A. Bergougnou, J. S. Peter-Castle, W. L. } \\
\text { Cairns, I. I. Inculet. } \\
\text { Breakdown of Air over a Water Surface Stressed by a Perpendicular } \\
\text { Alternating Electric Field. Proc. } \\
\text { (2000) IEEE International Symposium on Electrical Insulation, Anaheim CA, } \\
\text { USA, 2-5 April, 1, } 25 \text {. }\end{array}$ \\
\hline 3 & $\begin{array}{l}\text { Xu, X.P., Kushner, M.J. } \\
\text { Ion composition of expanding microdischarges in diele } \\
\text { charges } \\
\text { (1998) Journal of Applied Physics, } 83 \text { (12), pp. 7522- } \\
\text { DOI: } 10.1063 / 1.367515\end{array}$ \\
\hline 4 & $\begin{array}{l}\text { Dielectric-Barrier Discharges. Principle and Applications } \\
\text { U. Kogelschatz, B. Eliasson, W. Egli } \\
\text { J. Phys. IV France } 07 \text { (C4) C4-47-C4-66 (1997) } \\
\text { DOI: } 10.1051 / j p 4: 1997405\end{array}$ \\
\hline 5 & $\begin{array}{l}\text { Haverlag, M., Kroesen, G., Ferguson, I. } \\
\text { Special Issue on advanced and emerging light sources } \\
\text { (2011) Journal of Physics D: Applied Physics, } 44 \text { (22) } \\
\text { DOI: } 10.1088 / 0022-3727 / 44 / 22 / 220301\end{array}$ \\
\hline 6 & $\begin{array}{l}\text { Brandenburg, R. } \\
\text { Dielectric barrier discharges: Progress on plasma sources and on the un- } \\
\text { derstanding of regimes and single filaments } \\
\text { (2017) Plasma Sources Science and Technology, } 26 \text { (5). } \\
\text { DOI: } 10.1088 / 1361-6595 / \text { aa6426 }\end{array}$ \\
\hline 7 & $\begin{array}{l}\text { Ma, S., Zhao, Y., Yang, J., Zhang, S., Zhang, J., Zheng, C. } \\
\text { Research progress of pollutants removal from coal-fired flue gas using } \\
\text { non-thermal plasma } \\
\text { (2017) Renewable and Sustainable Energy Reviews, 67, pp. 791-810. } \\
\text { DOI: } 10.1016 / j . r s e r .2016 .09 .066\end{array}$ \\
\hline 8 & $\begin{array}{l}\text { Kim, H.-H. } \\
\text { Nonthermal plasma processing for air-pollution control: A historical re- } \\
\text { view, current issues, and future prospects } \\
\text { (2004) Plasma Processes and Polymers, 1 (2), pp. 91-110. } \\
\text { DOI: } 10.1002 / \text { ppap. } 200400028\end{array}$ \\
\hline 9 & $\begin{array}{l}\text { Wang, J.-J., Choi, K.-S., Feng, L.-H., Jukes, T.N., Whalley, R.D. } \\
\text { Recent developments in DBD plasma flow control } \\
\text { (2013) Progress in Aerospace Sciences, 62, pp. 52-78. } \\
\text { DOI: } 10.1016 / j . p a e r o s c i .2013 .05 .003\end{array}$ \\
\hline & $\begin{array}{l}\text { Cosson, B., Schmidt, F., Le Maoult, Y., Bordival, M. } \\
\text { Infrared heating stage simulation of semi-transparent media (PET) using } \\
\text { ray tracing method } \\
\text { (2011) International Journal of Material Forming, } 4 \text { (1), pp. 1-10. } \\
\text { DOI: } 10.1007 / \text { s12289-010-0985-8 }\end{array}$ \\
\hline
\end{tabular}




\begin{tabular}{|c|c|}
\hline & $\begin{array}{l}\text { Rasche, S., Begemann, M., Hopmann, Ch. } \\
\text { Modelling IR-heating in stretch-blow moulding and thermoforming } \\
\text { (2012) ASME } 2012 \text { 11th Biennial Conference on Engineering Systems De } \\
\text { and Analysis, ESDA 2012, 2, pp. 683-692. } \\
\text { DOI: } 10.1115 / \text { ESDA2012-82590 }\end{array}$ \\
\hline 12 & $\begin{array}{l}\text { Michaeli, W., Leopold, T. } \\
\text { Influence of the pet material grade on the energy eff } \\
\text { heat phase in the two-stage stretch blow moulding pro } \\
(2010) \text { Journal of Polymer Engineering, } 30 \text { (9), pp. } 58 \\
\text { mes. } \\
\text { DOI: } 10.1515 / \text { POLYENG.2010.30.9.587 }\end{array}$ \\
\hline 13 & $\begin{array}{l}\text { Erbulut, D.U., Masood, S.H., Senko, H., Davies, K. } \\
\text { Preheating of a poly (ethylene terephthalate) preform for stretch blow } \\
\text { molding using microwaves } \\
\text { (2009) Journal of Applied Polymer Science, } 112 \text { (3), pp. } 1670-1679 \text {. } \\
\text { DOI: } 10.1002 \text { /app.29576 }\end{array}$ \\
\hline 14 & $\begin{array}{l}\text { Ernst, G.J. } \\
\text { Compact uniform fie } \\
(1983) \text { Optics Commu } \\
\text { DOI: } 10.1016 / 0030-4\end{array}$ \\
\hline 15 & $\begin{array}{l}\text { Ashpis, D.E., Laun, M.C., Griebel } \\
\text { Progress toward accurate measurem } \\
\text { actuators } \\
\text { (2012) } 50 \text { th AIAA Aerospace Scienc } \\
\text { Forum and Aerospace Exposition, a } \\
\text { DOI: } 10.2514 / 6.2012-823\end{array}$ \\
\hline 16 & $\begin{array}{l}\text { Hołub, M. } \\
\text { on the measurement of plasma power in atmospheric pressure DBD plasma re- } \\
\text { actors } \\
(2012) \text { International Journal of Applied Electromagnetics and Mechanics, } \\
39(1-4), \mathrm{pp} \cdot 81-87 \\
\text { DOI: } 10.3233 / \mathrm{JAE}-2012-1446\end{array}$ \\
\hline 17 & $\begin{array}{l}\text { olub, Marcin. (2012). On the measurement of plasma power in atmospheric } \\
\text { ressure DBD plasma reactors. International Journal of Applied Electro- } \\
\text { agnetics and Mechanics. 39. 81-87. 10.3233/JAE-2012-1446. }\end{array}$ \\
\hline 18 & $\begin{array}{l}\text { Rao, Junfeng \& Liu, Kefu \& Qiu, Jian. (2012). An efficient all solid- } \\
\text { state pulsed generator for pulsed discharges. Proceedings of the } 2012 \\
\text { IEEE International Power Modulator and High Voltage Conference, IPMHVC } \\
\text { 2012. 473-476. 10.1109/IPMHVC.2012.6518783. }\end{array}$ \\
\hline 19 & $\begin{array}{l}\text { Truong HT, Hayashi M, Uesugi Y, Tanaka Y, Ishijima T. Novel design of high } \\
\text { voltage pulse source for efficient dielectric barrier discharge generation } \\
\text { by using silicon diodes for alternating current. Rev Sci Instrum. } 2017 \\
\text { Jun;88(6):065105. doi: } 10.1063 / 1.4984947 \text {. }\end{array}$ \\
\hline 20 & $\begin{array}{l}\text { Z. Salam, M. Facta, M. Amjad and Z. Buntat, "Design and implementation of } \\
\text { a low cost, high yield dielectric barrier discharge ozone generator based } \\
\text { on the single switch resonant converter," in IET Power Electronics, vol. } \\
\text { 6, no.8, pp. 1583-1591, September 2013. doi: 10.1049/iet-pel.2012.0470. }\end{array}$ \\
\hline 21 & $\begin{array}{l}\text { John A Thornton, Substrate heating in cylindrical magnetron sputtering } \\
\text { sources, Thin Solid Films, Volume 54, Issue 1, 1978, Pages 23-31, ISSN 0040- } \\
6090 \text {. }\end{array}$ \\
\hline & Juova Elettronica, anno 27, n. 177-178, febbraio-marzo 1995, Pages 100-114. \\
\hline
\end{tabular}

